\title{
ANTIBIOTIC RESISTANCE PROFILING OF DAIRY WASTEWATER DEGRADING NATIVE EFFICIENT MICROBIAL ISOLATES
}

\author{
ANUPAMA BHARDWAJ*, JAGTAR SINGH, SONIA CHAMAN, AMIT JOSHI \\ Department of Biotechnology, Panjab University, Chandigarh, Punjab, India. Email: anupamabhardwaj25@yahoo.co.in
}

Received: 13 March 2017, Revised and Accepted: 13 April 2017

ABSTRACT

Objective: The objective of this study is to make sure biotreatment process used for treatment of dairy wastewater (DWW) is safe for human and its surrounding environment; microbes were evaluated for their antibiotic resistance profile against commonly prescribed antibiotics.

Methods: Microbes were isolated using spread plating and streaking method and used to treat DWW. Reduction in organic load in DWW was determined by comparing physicochemical parameters (PCP) of DWW before and after treatment process. After selection of efficient microbial isolates, they were evaluated for their antibiotic resistance profile using antibiotic disc diffusion method.

Results: In this work, 53 microbes were isolated from DWW, and these microbial isolates were screened for DWW degradation capacity by analyzing PCP. Four microbial isolates E3, E5, E11 (bacterial isolates) and F5 (fungal isolate) showed highest reduction in chemical oxygen demand (COD), biological oxygen demand (BOD), and dissolved oxygen (DO) were selected for profound degradation of DWW under optimized conditions. Efficient four microbial isolates individually performed better under anaerobic conditions by showing maximum reduction 84\%, 75\%, and 77\% in COD, BOD, and DO, respectively. After 72 hrs of antibiotic susceptibility testing, E3 strain had shown 100\%, E5 90\%, E11 70\%, and F5 80\% susceptibility to antibiotics.

Conclusion: The present study concluded that four microbial isolates had the potential of reducing the organic load of DWW along with lessor or negligible adverse effect on human or its surrounding environment and they appear to be most promising strains for treatment of DWW.

Keywords: Dairy wastewater, Biological treatment, Antibiotic resistance, Microbial isolates.

(C) 2017 The Authors. Published by Innovare Academic Sciences Pvt Ltd. This is an open access article under the CC BY license (http://creativecommons. org/licenses/by/4. 0/) DOI: http://dx.doi.org/10.22159/ajpcr.2017.v10i7.18444

\section{INTRODUCTION}

For the two successive years 2015-2016, India faced drought. India's agriculture sector employ's $60 \%$ of the population and therefore drought mainly affects agriculturist or farmers. During this period, 330 million people of middle India were affected by it. To overcome this major problem, there is an urgent need to save water. Thus, treated wastewater should be reused for irrigation purposes and to maintain underground water table.

Dairy industry is one of the major food industries in India. The dairy sector in India, on an average has been reported to generate $0.2-10 \mathrm{l}$ of wastewater per liter of the milk processed [1]. However, careless use of wastewater can cause health problems to farmers, and there have been instances where farmers using untreated sewage showed the prevalence of diarrheal and skin diseases and infections. It is always better to treat sewage before irrigation as runoff from sewage can pollute streams, water bodies, and groundwater. About 73,000 ha of peri-urban agriculture in India use wastewater for irrigation. Treated wastewater should be made available for non-potable urban uses such as flushing, cleaning, gardening, and for industries.

Biological treatment using trickling filters and activated sludge process are efficient in complete removal of organic load from dairy wastewater (DWW) but are non-economical because more chemical consumption and large area are required for treatment process [2]. To enable dairy industry to contribute in water conservation, an efficient and costeffective treatment technology has to be developed [3]. Many studies on the degradation of DWW with microbes have been reported. Among the wastewater parameters, biological oxygen demand (BOD) and chemical oxygen demand (COD) are widely used as a primary indicator to gauge water pollution.
Work on getting efficient and more economical treatment process to treat DWW are still going on worldwide. In the previous studies, an optimization model for microbial mediated degradation of oil [4], diesel [5], endosulfan [6], and textile dye [7] has been reported. Today, at global level healthcare is facing the problem of the emergence of multi-resistant bacteria thus the threat of epidemics and pandemics [8] and became a major global health problem $[9,10]$. Hence, the present study was designed to isolate native DWW degrading microbes under optimized conditions and treatment of DWW under aerobic and anaerobic conditions and determination of antimicrobial resistance profile of efficient strains by disc diffusion method.

\section{METHODS}

\section{Sample collection}

Fresh untreated DWW was obtained from effluent treatment plant of dairy industry Verka, Mohali, Punjab, India in two different seasons of summer (August, May) and winter (November, February). Composite sampling was performed according to standard procedures from American Public Health Association (APHA, 1989) [11].

\section{Procurement of chemicals}

All the chemicals and analytical reagent grade were commercially procured from HIMEDIA ${ }^{\circledR}$, LobaChemi ${ }^{\circledR}$, SRL ${ }^{\circledR}$ (Sisco Research Laboratories) and Qualigens ${ }^{\circledR}$ and used as received without further modification. Double-distilled water was filtered through a Millipore membrane filter before being used.

\section{Analysis of physicochemical parameters (PCP) of DWW}

Season wise collected fresh untreated DWW samples were analyzed to determine their PCP. The analysis was done according to APHA, 1989. PCP such as salinity, conductivity, and total dissolved solids (TDS) was 
determined using "water quality analyzer" kit (Electronics India make) with resolution value for salinity $0.01 \mathrm{ppm}$, conductivity $0.01 \mathrm{~ms}$, and TDS $0.01 \mathrm{ppm}$. While organic load was determined by analyzing BOD, dissolved oxygen (DO), and COD using titer metric methods $[12,13]$.

\section{Isolation of the microbes}

Microbes were isolated from the dairy effluent (DE) samples collected in different season by Koch method based on the serial dilution and spreading on nutrient agar media (composition $\mathrm{gl}^{-1}$ : Peptic digest of animal tissue [5.0], sodium chloride [5.0], beef extract [1.5], yeast extract [1.5], agar [15.0]) and PDA (composition gl-1 ${ }^{-1}$ : Potatoes, infusion form [200.0], dextrose [20.0], agar [15.0]). From the individual colonies resulted on the media, bacterial and fungal pure cultures were obtained by inoculation in test tubes with sloping medium surface at $37 \pm 1.0^{\circ} \mathrm{C}$, $48 \mathrm{hrs}$ and $25 \pm 1.0^{\circ} \mathrm{C}, 72 \mathrm{hrs}$, respectively [3].

\section{Inoculum preparation}

To study the biodegradation efficiency of the bacterial isolates, each bacterial isolate with $0.1 \mathrm{ml}$ suspension with cell density $3.1 \times 10^{5} \mathrm{CFU} \mathrm{ml}^{-1}$ was inoculated in $100 \mathrm{ml}$ nutrient broth (composition $\mathrm{gl}^{-1}$ : Peptic digest of animal tissue [5.0], sodium chloride [5.0], beef extract [1.5], yeast extract [1.5]). Similarly, $0.1 \mathrm{ml}$ suspension of fungal isolate was inoculated in $100 \mathrm{ml}$ potato dextrose broth (composition gl${ }^{-1}$ : Potatoes, infusion form [200.0], dextrose [20.0]). The flask was kept on rotary shaker at $150 \mathrm{rpm}$ for 3 days at $25^{\circ} \mathrm{C}$. The flasks were kept on rotary shaker at $150 \mathrm{rpm}$ for $24-72 \mathrm{hrs}$ at $37 / 25^{\circ} \mathrm{C}$. Actively growing microbial culture of each isolate was centrifuged at 10,000 rpm for 10 minutes to get wet pellet of each isolate and it was washed thrice with sterile distilled water. The pellet was resuspended in sterile deionized water till turbidity reaches at or above that of McFarland 0.5 standard [3].

\section{Screening of DWW degrading bacterial isolates}

Season wise isolated microbial isolates were further screened for their DWW degradation efficiency to reduce PCP. The reduction potential of selected isolates was collectively analyzed for the treatment of DWW recollected in the month of May. Individual bacterial isolate with 2.5\% inoculum concentration was inoculated in $250 \mathrm{ml}$ Erlenmeyer flask containing $100 \mathrm{ml}$ of DWW at pH 7 at $32^{\circ} \mathrm{C}$ for $24 \mathrm{hrs}$ on a rotary shaker at $150 \mathrm{rpm}$ and $2.5 \%$ concentration of individual fungal isolate inoculated in $100 \mathrm{ml} \mathrm{DWW}$ at pH 6 for $72 \mathrm{hrs}$. After $24 \mathrm{hrs}$ (bacteria) and $72 \mathrm{hrs}$ (fungi), samples were taken from each flask, and physicochemical analysis was done. Percentage reduction in COD, BOD, DO, TDS, salinity, and electrical conductivity was calculated and the bacterial isolates exhibiting more than $45 \%$ reduction ability and fungal isolate having more than $25 \%$ reduction ability were selected for further optimization experimentation.

The percentage reduction was calculated by:

$$
\% \text { Reduction }=\frac{\text { Initial value }- \text { final value }}{\text { Initial value }} \times 100
$$

Optimized treatment of DWW by native microbial isolates under aerobic and aerobic conditions

To achieve the highest reduction rate of the organic load by the selected isolates of microbes different media parameters were optimized. Preliminary studies were conducted to select the standard conditions such as inoculum concentration, incubation period, $\mathrm{pH}$, and temperature. All the experiments were conducted in triplicate. The reduction was determined by taking aliquots after optimum incubation period, and PCP were analyzed before and after treatment process [14]. After optimization DWW was treated aerobically and anaerobically under optimized conditions.

\section{Determination of antibiotic resistance pattern of DWW degrading} microbial isolates

The antibiotic resistance was determined by standard agar disc diffusion method on nutrient agar using commercial discs (Hi-Media, Mumbai, India). $100 \mu \mathrm{l}$ of fresh bacterial and fungal cultures were spread on nutrient agar plates. Antibiotic discs were placed on the plate, within 15 minutes of the application of the discs, the plates were inverted and incubated at $37^{\circ} \mathrm{C}$ for bacteria and $28^{\circ} \mathrm{C}$ for fungi. The plates were examined after $24 \mathrm{hrs}$ of incubation for bacteria and after 96 hrs of incubation for fungi, and the diameters of the zones of complete inhibition to the nearest whole millimeter were measured. The zone diameter for individual antimicrobial agents was then translated into sensitive and resistant categories [15].

\section{RESULTS AND DISCUSSION}

\section{Isolation and screening of DWW degrading bacteria}

Microbes were isolated from wastewater samples collected in different seasons by spread plating and streaking technique. From winter season (November and February), 21 bacteria and 7 fungi were isolated while from summer season (May and August) 18 bacteria and 6 were isolated. All the bacterial and fungal isolates were analyzed for their COD, BOD, DO, TDS, salinity and electrical conductivity reduction efficiency. Out of 39 bacterial isolates, 14 bacterial strains showed significant degradation of effluent in terms of percentage reduction in PCP while out of 13 fungal isolates 6 fungal isolates were efficient in reducing PCP.

These 14 bacterial isolates and 6 fungal isolates were collectively reused to treat fresh DWW collected in the month of May and to confirm their reduction potential. Bacterial treatment was carried out with $2.5 \%$ inoculum concentration, $\mathrm{pH} 7.0$, at $32^{\circ} \mathrm{C}$ for $24 \mathrm{hrs}$ while fungal treatment was carried out with $2.5 \%$ inoculum concentration, $\mathrm{pH} 6.0$, at $25^{\circ} \mathrm{C}$ for $72 \mathrm{hrs} 14$ bacterial isolates and 6 fungal isolates showed variable potential to reduce PCP (Table 1).

Out of 14 bacterial isolates, only 5 isolates reduced more than $45 \%$ COD while 6 and 9 bacteria reduced more than 50\% BOD and DO respectively after $24 \mathrm{hrs}$. These isolates showed a different range of reduction potential for COD (16-58\%), BOD (35-55\%), DO (41-57\%), TDS $(22-61 \%)$, conductivity (5-56\%), and salinity $(28-62 \%)$ as compared to the initial value of sample (taken as control). It is evident from the results (Table 1) that the COD, BOD, and other parameters of effluent after biotreatment were significantly reduced by E3, E5, E6, E9, and E11. These 5 bacterial isolates showed more than $45 \%$ reduction in COD, BOD, DO. Percentage reduction in COD, BOD, DO of these isolates were E3 $(58,54,57), \mathrm{E} 11(48,54,52), \mathrm{E} 6(47,54,54), \mathrm{E} 5(47,49,53)$, and E9 $(45,55,55)$. The strain E14 showed minimum reduction potential of PCP. Significant reduction in PCP was observed after bacteria-mediated

Table 1: Percentage reduction in PCP of dairy wastewater after treatment with selected degrading bacterial isolates

\begin{tabular}{|c|c|c|c|c|c|c|c|c|c|c|c|c|c|c|}
\hline \multirow[t]{2}{*}{ PCP } & \multicolumn{3}{|c|}{ November } & \multicolumn{5}{|c|}{ February } & \multicolumn{2}{|c|}{ May } & \multicolumn{4}{|c|}{ August } \\
\hline & $E_{1}$ & $\mathbf{E}_{2}$ & $\mathbf{E}_{3}$ & $E_{5}$ & $E_{6}$ & $\mathbf{E}_{7}$ & $E_{8}$ & $\mathbf{E}_{9}$ & $E_{10}$ & $E_{11}$ & $\mathrm{E}_{12}$ & $E_{13}$ & $E_{14}$ & $E_{15}$ \\
\hline COD mg l-1 & 33 & 42 & 58 & 47 & 47 & 23 & 18 & 45 & 44 & 48 & 16 & 34 & 18 & 17 \\
\hline BOD mg l-1 & 50 & 51 & 54 & 49 & 54 & 40 & 35 & 55 & 50 & 53 & 38 & 51 & 36 & 35 \\
\hline $\mathrm{DO} \mathrm{mg} \mathrm{l}^{-1}$ & 52 & 54 & 57 & 53 & 54 & 51 & 41 & 55 & 54 & 52 & 41 & 48 & 44 & 42 \\
\hline TDS (ppt) & 22 & 61 & 40 & 47 & 42 & 49 & 41 & 36 & 44 & 55 & 39 & 32 & 36 & 55 \\
\hline Conductivity $(\mathrm{mS})$ & 47 & 5 & 56 & 43 & 41 & 30 & 24 & 45 & 53 & 41 & 23 & 41 & 36 & 26 \\
\hline Salinity(ppt) & 50 & 52 & 62 & 50 & 55 & 39 & 56 & 56 & 58 & 50 & 28 & 49 & 39 & 38 \\
\hline
\end{tabular}

PCP: Physicochemical parameters, COD: Chemical oxygen demand, BOD: Biological oxygen demand, TDS: Total dissolved solids, DO: Dissolved oxygen, ppt: Precipitate, $\mathrm{mS}$ : Siemens per meter 
treatment could be associated with consumption of organic material by bacteria as a food source.

Only 2 fungal isolates F4 and F5 were able to reduced COD above 10\% after 72 hrs of treatment. These isolates showed a different range of reduction potential for COD (1-13\%), BOD (2-20\%), DO (5-26\%), TDS (43-75\%), conductivity (39-47\%), and salinity (22-48\%) as compared to the initial value of sample (taken as control). It is evident from the results (Table 2) that the COD, BOD, and other parameters of effluent after biotreatment were significantly reduced by F5.

Optimized treatment of DWW by native microbial isolates under aerobic and aerobic conditions

E3, E5, and E9 were isolated from DWW samples of winter season while E11 was isolated from summer season. It was observed that native DWW bacterial population of winter season was more efficient DWW degrader as compared to summer season bacterial population. Efficient fungal isolate F5 was isolated from summer season dairy sample. Maximum percentage reduction in COD, BOD, DO, salinity, and conductivity were achieved by E3 of winter season followed by E11 of summer season and E5 of winter season. Along with fungal isolate F5, these three bacterial isolates were found to be the most efficient in biotreatment of DWW.

Under aerobic conditions maximum percentage reduction in PCP such as COD, BOD, DO, TDS, conductivity and salinity were achieved with

Table 2: Percentage reduction in PCP of dairy wastewater after treatment with selected degrading fungal

\begin{tabular}{|c|c|c|c|c|c|c|}
\hline \multirow[t]{2}{*}{ PCP } & \multirow{2}{*}{$\begin{array}{l}\text { November } \\
F_{1}\end{array}$} & \multicolumn{2}{|c|}{ February } & \multicolumn{2}{|c|}{ May } & \multirow{2}{*}{$\begin{array}{l}\text { August } \\
F_{6}\end{array}$} \\
\hline & & $\mathbf{F}_{2}$ & $\mathbf{F}_{3}$ & $\mathrm{~F}_{4}$ & $\mathbf{F}_{5}$ & \\
\hline COD mg/l & 1 & 7 & 6 & 13 & 13 & 7 \\
\hline BOD mg/l & 2 & 10 & 9 & 15 & 20 & 7 \\
\hline DO mg/l & 5 & 13 & 17 & 19 & 26 & 20 \\
\hline TDS (ppt) & 75 & 73 & 63 & 50 & 43 & 57 \\
\hline Conductivity (mS) & 44 & 43 & 47 & 44 & 39 & 44 \\
\hline Salinity (ppt) & 48 & 41 & 39 & 26 & 22 & 37 \\
\hline
\end{tabular}

PCP: Physicochemical parameters, COD: Chemical oxygen demand, BOD: Biological oxygen demand, DO: Dissolved oxygen, TDS: Total dissolved solids, ppt: Precipitate, mS: Siemens per meter
E3 $(66,64,66,19,60,53)$, E5 $(58,64,64,34,52,52)$, E9 $(47,59,58,12$, $41,42)$, E11 $(62,65,66,52,22,53)$, and F5 $(72,62,64,42,29,42)$. On the basis of percentage reduction in PCP shown by microbial isolates E3, E5, E11, and F5 were considered more efficient in degrading DWW.

Under anaerobic conditions maximum percentage reduction in PCP such as COD, BOD, DO, TDS, conductivity and salinity was achieved with E3 $(78,75,77,32,69,61)$, E5 $(70,72,72,48,72,62)$, E9 $(34,44,44,9$, $34,35), \mathrm{E} 11(76,72,75,44,68,64)$, and F5 $(84,70,75,50,44,54)$. On the basis of percentage reduction in PCP shown by microbial isolates E3, E5, E11, and F5 were considered more efficient in degrading DWW.

As shown in Tables 3 and 4, it is clear that microbial isolates performed better under anaerobic conditions. Anaerobic process is cost-effective approach as compared to aerobic process in which air should be continuously supplied from outside to bioreactor.

Determination of antibiotic resistance pattern of DWW degrading bacterial and fungal isolates

Four efficient degrading strains were selected on the basis of their PCP reducing capability. These selected strains were further evaluated for their antibiotic resistance pattern to make sure they are humanfriendly or will have to take some measures while working with them. To get ensure about the bacteria used for biodegradation is harmless to the environment these bacteria were evaluated for their resistance and susceptible pattern against ten commonly prescribed clinically significant antibiotics, namely, tetracycline (TC), cefotaxime (CT), amikacin (AK), cefixime (CF), ampicillin (AM), penicillin (PC), gentamicin $(\mathrm{GM})$, cloxacillin (CX), erythromycin (ER), and chloramphenicol $(\mathrm{CH})$ using antibiotic disc diffusion method. To get ensure about the fungi used for biodegradation is harmless to the environment and these fungi were evaluated for their resistance and susceptible pattern against five commonly prescribed clinically significant antibiotics, namely, voriconazole (VC), oleandomycin (OM), fluconazole (FZ), terbinafine (TF), and itraconazole (IZ) (Tables $5 \mathrm{a}$ and $\mathrm{b}, 6$ ).

Data revealed that all isolates show the variable sensitivities against the different antibiotics used in the study. After 24 hrs of antibiotic susceptibility testing E3 strain had shown 70\%, E5 60\%, E11 50\% and F5 $0 \%$ susceptibility to antibiotics. After $48 \mathrm{hrs}$ of antibiotic susceptibility testing, E3 strain had shown 80\%, E5 70\%, E11 50\%,

Table 3: Percentage reduction of PCP of dairy wastewater by selected efficient degrading isolates at respective optimized media parameters under aerobic conditions

\begin{tabular}{|c|c|c|c|c|c|c|c|c|c|c|}
\hline \multirow[t]{2}{*}{ Bacterial isolates } & \multicolumn{4}{|c|}{ Optimized media parameters } & \multicolumn{6}{|c|}{ Percentage reduction of PCP } \\
\hline & $\begin{array}{l}\text { Inoculum concentration } \\
100 \mathrm{ml}^{-1}\end{array}$ & Incubation period & pH & Temperature $\left({ }^{\circ} \mathrm{C}\right)$ & COD & BOD & DO & TDS & Conductivity & Salinity \\
\hline E3 & 2.5 & $48 \mathrm{hrs}$ & 7 & 37 & 66 & 64 & 66 & 19 & 60 & 53 \\
\hline E5 & 3.0 & $48 \mathrm{hrs}$ & 4 & 50 & 58 & 64 & 64 & 34 & 52 & 52 \\
\hline E9 & 2.5 & $48 \mathrm{hrs}$ & 7 & 37 & 47 & 59 & 58 & 12 & 41 & 42 \\
\hline E11 & 3.0 & $48 \mathrm{hrs}$ & 4 & 15 & 62 & 65 & 66 & 52 & 22 & 53 \\
\hline F5 & 2.5 & 6 days & 7 & 30 & 72 & 62 & 64 & 42 & 29 & 42 \\
\hline
\end{tabular}

PCP: Physicochemical parameters, COD: Chemical oxygen demand, BOD: Biological oxygen demand, DO: Dissolved oxygen, TDS: Total dissolved solids

Table 4: Percentage reduction of PCP of dairy wastewater by selected efficient degrading isolates at respective optimized media parameters under anaerobic conditions

\begin{tabular}{|c|c|c|c|c|c|c|c|c|c|c|}
\hline \multirow[t]{2}{*}{ Bacterial isolates } & \multicolumn{4}{|c|}{ Optimized media parameters } & \multicolumn{6}{|c|}{ Percentage reduction of PCP } \\
\hline & $\begin{array}{l}\text { Inoculum concentration } \\
100 \mathrm{ml}^{-1}\end{array}$ & Incubation period & pH & Temperature $\left({ }^{\circ} \mathrm{C}\right)$ & COD & BOD & Do & TDS & Conductivity & Salinity \\
\hline E3 & 2.5 & $48 \mathrm{hrs}$ & 7 & 37 & 78 & 75 & 77 & 32 & 69 & 61 \\
\hline E5 & 3.0 & $48 \mathrm{hrs}$ & 4 & 50 & 70 & 72 & 72 & 48 & 72 & 62 \\
\hline E9 & 2.5 & $48 \mathrm{hrs}$ & 7 & 37 & 34 & 44 & 44 & 9 & 34 & 35 \\
\hline E11 & 3.0 & $48 \mathrm{hrs}$ & 4 & 15 & 76 & 72 & 75 & 44 & 68 & 64 \\
\hline
\end{tabular}

PCP: Physicochemical parameters, COD: Chemical oxygen demand, BOD: Biological oxygen demand, DO: Dissolved oxygen, TDS: Total dissolved solids 
Table 5a: The antibiotic susceptibility pattern of the bacterial isolates

\begin{tabular}{|c|c|c|c|c|c|c|c|c|c|c|c|c|c|c|c|}
\hline \multirow{3}{*}{$\begin{array}{l}\text { Incubation } \\
\text { period (hrs) }\end{array}$} & \multicolumn{15}{|c|}{ ZOI* against antibiotics } \\
\hline & \multicolumn{3}{|l|}{ TC } & \multicolumn{3}{|l|}{ CT } & \multicolumn{3}{|l|}{ AK } & \multicolumn{3}{|l|}{ CF } & \multicolumn{3}{|l|}{ AM } \\
\hline & 24 & 48 & 72 & 24 & 48 & 72 & 24 & 48 & 72 & 24 & 48 & 72 & 24 & 48 & 72 \\
\hline E3 & 11 & 13 & 13 & 14 & 14 & 14 & 17 & 17 & 19 & 11 & 11 & 13 & 13 & 14 & 17 \\
\hline E5 & 08 & 11 & 12 & - & - & - & 12 & 12 & 20 & 07 & 10 & 14 & 14 & 14 & 14 \\
\hline E11 & 15 & 25 & 25 & 16 & 20 & 20 & 20 & 20 & 20 & 16 & 16 & 16 & 09 & 09 & 09 \\
\hline
\end{tabular}

*Zone of inhibition in mm, TC: Tetracycline, CT: Cefotaxime, AK: Amikacin, CF: Cefixime, AM: Ampicillin

Table 5b: The antibiotic susceptibility testing of the bacterial isolates

\begin{tabular}{|c|c|c|c|c|c|c|c|c|c|c|c|c|c|c|c|}
\hline \multirow{3}{*}{$\begin{array}{l}\text { Incubation } \\
\text { period (hrs) }\end{array}$} & \multicolumn{15}{|c|}{ ZOI* against antibiotics } \\
\hline & \multicolumn{3}{|l|}{ PC } & \multicolumn{3}{|c|}{ GM } & \multicolumn{3}{|l|}{ CX } & \multicolumn{3}{|l|}{ ER } & \multicolumn{3}{|l|}{$\mathbf{C H}$} \\
\hline & 24 & 48 & 72 & 24 & 48 & 72 & 24 & 48 & 72 & 24 & 48 & 72 & 24 & 48 & 72 \\
\hline E3 & 10 & 10 & 12 & 12 & 14 & 15 & 17 & 17 & 17 & 16 & 23 & 30 & 18 & 24 & 24 \\
\hline E5 & 12 & 12 & 12 & - & 18 & 18 & 17 & 20 & 20 & 21 & 21 & 21 & 12 & 13 & 13 \\
\hline E11 & - & - & - & 10 & 11 & 12 & - & - & - & 09 & 11 & 14 & 18 & 24 & 26 \\
\hline
\end{tabular}

*Zone of inhibition in mm, PC: Penicillin, GM: Gentamicin, CX: Cloxacillin, ER: Erythromycin, CH: Chloramphenicol

Table 6: The antibiotic susceptibility testing of the fungal isolates

\begin{tabular}{|c|c|c|c|c|c|c|c|c|c|c|c|c|c|c|c|}
\hline \multirow{3}{*}{$\begin{array}{l}\text { Incubation } \\
\text { period (hrs) }\end{array}$} & \multicolumn{15}{|c|}{ ZOI* against antibiotics } \\
\hline & \multicolumn{3}{|l|}{ VC } & \multicolumn{3}{|l|}{$\mathbf{O M}$} & \multicolumn{3}{|l|}{ FZ } & \multicolumn{3}{|l|}{ TF } & \multicolumn{3}{|l|}{ IZ } \\
\hline & 24 & 48 & 72 & 24 & 48 & 72 & 24 & 48 & 72 & 24 & 48 & 72 & 24 & 48 & 72 \\
\hline F5 & - & - & 13 & - & - & - & - & 8 & 14 & - & - & 12 & - & 6 & 15 \\
\hline
\end{tabular}

*Zone of inhibition in mm, VC: Voriconazole, OM: Oleandomycin, FZ: Fluconazole, TF: Terbinafine, IZ: Itraconaz

and F5 40\% susceptibility to antibiotics. After $72 \mathrm{hrs}$ of antibiotic susceptibility testing, E3 strain had shown 100\%, E5 90\%, E11 70\%, and F5 $80 \%$ susceptibility to antibiotics. It has been also observed that after $72 \mathrm{hrs}$ all bacterial isolates were highly susceptible against six antimicrobial agents TC, AK, CF, GM, ER, and $\mathrm{CH}$ while fungal isolate $\mathrm{F} 5$ were highly susceptible against VC, FZ, TF, and IZ.

$\mathrm{AM}, \mathrm{PC}$, and $\mathrm{CX}$ were found to be most vulnerable antibiotics against which E11 shows 100\% resistance. CT was moderate antibiotics as one isolate (E5) has shown resistance against it. E3 strain had shown high biodegrading capacity and also $100 \%$ susceptible against ten antimicrobial agents. F5 were resistant against one antibiotic, i.e., OM. The bacteria that showed more resistance for antibiotics/antimicrobial agents as compared to other bacterial isolates is not suitable for use in bioremediation process because it can harm the surrounding environment and cannot be cured easily by the above-mentioned antibiotics treatment. The results provided one of safe assurance of using these strains to in situ bioremediation of DWW.

\section{CONCLUSION}

This investigation resulted in isolation and determination of antibiotic-resistant pattern of native DE degrading microbes. Under aerobic conditions E3, E5, E11, and F5 exhibited COD, BOD, and DO percentage reduction potential in the range $64-72 \%, 64-65 \%$, and 64-66\%, respectively while under anaerobic conditions E3, E5, E11, and F5 exhibited COD, BOD, and DO percentage reduction potential in the range $84-70 \%, 75-70 \%$, and $77-72 \%$, respectively. Microbial treatment of DWW is a good alternative to treat effluent with much less expenses, but before using any microbe, antibiotic resistance pattern of efficient strain should be checked out for our safety concern. E3, E5, E11, and F5 can be used in biodegradation without any hesitation because of their low resistance pattern. The present study evaluated the prevalence of antibiotic resistance among biodegrading microbial isolates from DE and determined their resistance patterns. The study of antibiotic resistance helps to predict future emergence and guide the development of strategies to counteract this resistance before their application in biodegradation process. Hence, our research work opens scope for sustainable reuse of huge amount of wastewater generated by dairy industry.

\section{ACKNOWLEDGMENT}

This research was financially supported by the University Grant Commission New Delhi under major research project grant (F.No. 39-268/2010 [SR]). The authors express gratitude to Principal, Head Department of Biotechnology, SGGS College and Panjab University, for their valuable support during the entire study.

\section{REFERENCES}

1. Dhall P, Siddiqi TO, Ahmad A, Kumar R, Kumar A. Restructuring BOD: COD ratio of dairy milk industrial wastewaters in BOD analysis by formulating a specific microbial seed. Sci World J 2012;2012:1-7.

2. Pathak U, Das P, Banerjee P, Datta S. Treatment of wastewater from a dairy industry using rice husk as adsorbent: Treatment efficiency, isotherm, thermodynamics, and kinetics Modelling. J Thermodyn 2016;2016:1-8.

3. Porwal HJ, Mane VA, Velhal GS. Biodegradation of dairy effluent by using microbial isolates obtained from activated sludge. World Resour Ind 2015;9:1-15.

4. Sirisha E, Rajasekar N, Narasu LM. Isolation and optimization of lipase producing bacteria from oil contaminated soils. Adv Biol Res 2010;4(5):249-52.

5. Mahalingam UP, Sampath N. Optimization of growth condition for diesel oil degrading bacterial strains. Adv Appl Sci Res 2014;5(6):91-6.

6. Jayanthi P, Prabhu S. Optimization studies on degradation of endosulfan by indigenous soil bacterial isolates. Int J Sci Res 2013;5(4):2014-8.

7. Prasad MP, Bhakat P, Chatterjee S. Optimization of textile dye degradation by bacterial species isolated from natural sources. J Ecol Environ Sci 2013;4(1):1-6.

8. Svahn KS, Göransson U, El-Seedi H, Bohlin L, Larsson DJ, Olsen B, et al. Antimicrobial activity of filamentous fungi isolated from highly antibiotic-contaminated river sediment. Inf Ecol Epidemiol 2012;2:1-6. 
9. Sharma A, Menghani E. Microorganisms as chemical factories for isolation of meta-bolomes from mesophilic soil. Int J Pharm Pharm Sci 2017;9(4):121-8

10. Zana I, Agim S, Ardiana M, Fehim H. The possibility of development of antibiotic resistance from massive and uncontrolled use of sulfonamides in milk. Int J Pharm Pharm Sci 2017;9(4):207-11.

11. Sonune NA, Mungal NA, Kamble SP. Study of physico-chemical characteristics of domestic wastewater in Vishnupuri, Nanded, India. Int J Curr Microbiol Appl Sci 2015;4(1):533-6.

12. Sawyer C, McCarty P, Parkin G. Chemistry for Environmental
Engineering and Science. $5^{\text {th }}$ ed. New York: McGraw-Hill; 2003.

13. Prasad MP, Manjunath K. Comparative study on biodegradation of lipid-rich wastewater using lipase producing bacterial species. IJBT Niscair 2010;10:121-4.

14. Davis KE, Joseph SJ, Janssen PH. Effects of growth medium, inoculum size, and incubation time on culturability and isolation of soil bacteria. Appl Environ Microbiol 2005;71(2):826-34.

15. Bhardwaj A, Chaman S. Antibiotic susceptibility of biodegrading bacterial isolates from dairy effluent. Int J Bioassays 2013;2(7):956-60. 